\title{
Temperature-induced volatility of molecular markers in ambient airborne particulate matter
}

\author{
C. R. Ruehl, W. A. Ham, and M. J. Kleeman \\ Department of Civil and Environmental Engineering, University of California, Davis, USA \\ Received: 30 July 2010 - Published in Atmos. Chem. Phys. Discuss.: 27 August 2010 \\ Revised: 16 November 2010 - Accepted: 7 December 2010 - Published: 4 January 2011
}

\begin{abstract}
Molecular markers are organic compounds used to represent known sources of particulate matter (PM) in statistical source apportionment studies. The utility of molecular markers depends on, among other things, their ability to represent PM volatility under realistic atmospheric conditions. We measured the particle-phase concentrations and temperature-induced volatility of commonly-used molecular markers in California's heavily polluted San Joaqin Valley. Concentrations of elemental carbon, organic carbon, levoglucosan, and polycyclic aromatic hydrocarbons were not reduced by mild $(\sim 10 \mathrm{~K})$ heating. In contrast, both hopane/sterane and $n$-alkane concentrations were reduced, especially during the summer sampling events at the urban site. These results suggest that hopanes and steranes have effective saturation concentrations $\sim 1 \mu \mathrm{g} \mathrm{m}^{-3}$, and therefore can be considered semi-volatile. The volatility of an individual compound depends both on its inherent properties (primarily vapour pressure) and the interactions between itself and any potential absorbing phase. The volatility behavior of $n$-alkanes during the urban summer is consistent with that predicted for absorption by suberic acid $\left(\mathrm{a}_{8}\right.$ diacid) using a group contribution modelling method. Observations can also be matched by an absorbent whose composition is based on recently-obtained high-resolution aerosol mass spectrometer factors (approximately 33\% "hydrocarbon-like" and 67\% oxygenated organic aerosol). The reduced evaporation of the $n$-alkanes, hopanes, and steranes with mild heating during rural and/or winter experiments could be explained by a more oxygenated absorbing phase along with a non-absorptive partitioning mechanism, such as adsorption to soot. This suggests that the temperature-induced volatility of large hydrocarbons in PM is most important if a relatively non-polar ab-
\end{abstract}

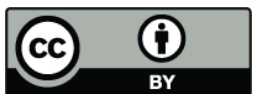

Correspondence to: M. J. Kleeman (mjkleeman@ucdavis.edu) sorbing organic phase exists. While the activity coefficients of most organic aerosol compounds may be close to unity, the assumption of ideality for large hydrocarbons (e.g., hopanes) may result in large errors in partitioning calculations.

\section{Introduction}

The design and evaluation of strategies to mitigate the negative effects of airborne particulate matter (PM) require source apportionment information. Statistical source apportionment techniques rely on the chemical signatures measured at receptor sites to quantify primary source contributions. Organic molecular markers have been especially useful for the source apportionment of carbonaceous aerosols (Schauer et al., 1996; Chow and Watson, 2002; Lin et al., 2010). Commonly-used organic molecular markers include hopanes and steranes for motor oil emissions (Simoneit, 1999, Phuleria et al. 2007; Riddle et al., 2008); heavy polycyclic aromatic hydrocarbons (PAHs) for gasoline exhaust (Riddle et al., 2008) and coal combustion (Robinson et al., 2006); light PAHs for diesel exhaust (Fraser et al., 2003; Riddle et al., 2008); cholesterol for food cooking (Rogge et al., 1991); $n$ alkanes for vegetative detritus (Rogge et al., 1993); and levoglucosan for biomass burning (Simoneit, 2002). In general, the utility of a marker compound depends on how unique it is to a source, and how conserved it is in the atmosphere (i.e., its volatility and/or reactivity) relative to the other primary mass emitted from that source.

Recent smog chamber experiments have suggested that molecular markers and some portion of primary PM emissions may be semi-volatile (Robinson et al., 2007, Lambe et al., 2009). These experiments have indicated that evaporation of primary emissions is coupled to their gas-phase oxidation (Lambe et al., 2009; Miracolo et al., 2010), in

Published by Copernicus Publications on behalf of the European Geosciences Union. 
part because photochemical lifetimes of larger, non-polar molecules in the gas phase (Atkinson and Arey, 2003) tend to be shorter than the timescale of diffusion of oxidants (e.g., the hydroxyl radical) to particles. This suggests that the volatility of primary molecular markers may also largely determine their stability in the atmosphere. Ideally, molecular markers from each source would evaporate (and/or react) at the same rate as the primary PM from that same source. Any mismatch between the volatility of the molecular markers and the primary PM mass could cause an under-prediction or over-prediction of source contributions. In some ways, the importance of molecular marker volatility has already been recognized. Several molecular markers formerly used in source apportionment calculations have been omitted from more recent studies due to their volatility (e.g., retene, Ramdahl, 1983 vs. Schauer and Cass, 2000). Still other studies have suggested that light semi-volatile PAHs may be too strongly bound to the particulate phase for significant volatilization to occur (Arp et al., 2008; Pankow and Bidleman, 1992). These examples illustrate the difficulty in using simple theories and/or smog chamber measurements to make a priori predictions about the most appropriate molecular markers for source apportionment studies in the real atmosphere. A need exists to quantify the volatility of molecular markers under realistic atmospheric conditions.

In the present study, urban (Fresno) and rural airborne PM samples from the San Joaquin Valley (California) were collected to study the volatility of commonly-used molecular markers. The San Joaquin valley (SJV), CA, experiences some of the highest airborne PM concentrations in the United States, especially in the winter when elevated temperature inversions create stagnation events lasting more than a week. Numerous source apportionment studies have been carried out in the SJV over the past decades (Chow et al., 1992; Magliano et al., 1999; Schauer and Cass, 2000; Rinehart et al., 2006; Chen et al., 2007; Chow et al, 2007; Kleeman et al., 2009). Earlier efforts apportioned the sources of $\mathrm{PM}_{10}$ (Chow et al., 1992), while more recent studies have focused on finer particles. All studies suggest a more regionally elevated secondary ammonium nitrate (AN) and/or organic aerosol in contrast to primary organic aerosols which show more spatial variability. Magliano et al. (1999) found that urban winter SJV $\mathrm{PM}_{2.5}$ came primarily from mobile sources, burning, AN, and at times "excess OC," assumed to comprise secondary OC as well as unaccounted primary sources. Rural winter $\mathrm{PM}_{2.5}$ was dominated by AN. Schauer and Cass (2000) used organic molecular markers in a chemical mass balance (CMB) model to determine that primary emissions account for $79 \%$ of urban $\mathrm{PM}_{2.5}$ but less than $10 \%$ of $\mathrm{PM}_{2.5}$ from a rural site in the SJV. Chow et al. (2007) found that inclusion of organic molecular markers in CMB analysis of Fresno (SJV) samples improved distinction between gasoline and diesel emissions, and precision of cooking emission estimates.
In the present study, airborne PM collection occurred at ambient temperatures and at approximately $10 \mathrm{~K}$ above ambient, during both the summer and winter. Samples were analyzed for thermal-optical elemental and organic carbon (EC and OC) concentrations. Molecular markers including PAHs, hopanes, steranes, levoglucosan, cholesterol, and $n$ alkanes were quantified by solvent extraction followed by gas chromatography-mass spectrometry (GC-MS). We compare the results between the ambient and heated samples, to determine if and when volatilization reduces particle-phase concentrations of molecular markers. We also use a groupcontribution activity model (Gmehling and Schiller, 1993) to compare different assumptions regarding the composition of the absorbent to observations, using observations of $n$-alkane volatility. As a well-characterized set of homologous organic compounds, $n$-alkanes are used as a probe of absorbent composition through their effect on solute activity (manifested as $n$-alkane volatility). Many researchers have assumed that absorption forms an ideal solution; we test this assumption in ambient aerosols by calculating the activity of $n$-alkanes in various model absorbents.

\section{Absorptive partitioning theory}

According to standard absorptive partitioning theory (Pankow, 1994), the concentration of a semi-volatile compound $i$ in an absorbing particulate organic matter phase depends on its total (gas + particle) concentration $\left(C_{i, \text { tot }}\right)$, its effective saturation concentration $\left(C_{i}^{*}\right)$, and the concentration of the absorbing particulate organic matter $\left(C_{\mathrm{abs}}\right)$

$C_{i, \text { abs }}=C_{i, \text { tot }}\left(1+\frac{C_{i}^{*}}{C_{\mathrm{abs}}}\right)^{-1}$.

The effective saturation concentration of a compound can be expressed in terms of its vapor pressure $\left(p_{i}^{0}\right)$, activity in the absorbing phase, and temperature $(T)$

$C_{i}^{*}=\frac{p_{i}^{0} \zeta_{i} \mathrm{MW}_{\mathrm{abs}}}{\mathrm{RT}}$,

where $\mathrm{MW}_{\mathrm{abs}}$ is the average molecular weight of the absorbing phase, $\zeta_{i}$ is the activity coefficient of the compound in that phase, and $R$ is the gas constant. Most of the uncertainty in estimates of atmospherically relevant $C_{i}^{*}$ is due to uncertainty in $p_{i}^{0}$ and $\zeta_{i}$, because uncertainty in these variables can exceed a factor of 10 (e.g., $p_{i}^{0}$ estimates for hopanes and other cyclic, branched alkanes, or $\zeta_{i}$ of large hydrocarbons in polar organic solvents). Although there is obviously uncertainty in ambient $\mathrm{MW}_{\mathrm{abs}}$ (and to a lesser extent, $T$ ), it will be secondary in terms of its impact on the theoretical value of $C_{i}^{*}$.

The fraction of a compound in the particle phase $\left(f_{\text {part }}\right)$ depends on $C_{i}^{*}$

$f_{i, \mathrm{part}}=\frac{C_{i, \mathrm{abs}}}{C_{i, \mathrm{tot}}}=\frac{1}{1+C_{i, \mathrm{amb}}^{*} / C_{\mathrm{abs}}}$. 
Neglecting the change in $C_{\mathrm{abs}}$ with mild heating, the fraction lost from the particle phase at a heated temperature ( $\left.T_{\text {heat }}\right)$ relative to ambient $\left(T_{\mathrm{amb}}\right)$ can be expressed in terms of the increase in $C_{i}^{*}$ with $T$ :

$f_{i, \text { lost }}=1-\left(1+\frac{C_{i, \mathrm{amb}}^{*}}{C_{\mathrm{abs}}}\right) /\left(1+\frac{C_{i, \text { heat }}^{*}}{C_{\mathrm{abs}}}\right)$.

By inserting the definition of $C_{i}^{*}$ (Eq. 2) into Eq. (5), $f_{i, \text { lost }}$ can be expressed in terms of the physiochemical properties of compound i, $T$, and the concentration and average MW of the absorbing phase:

$f_{i, \text { lost }}=1-\left(1+\frac{p_{\text {amb }}^{o} \zeta_{i, \text { amb }} \mathrm{MW}_{\mathrm{POM}}}{R T_{\mathrm{amb}} C_{\mathrm{abs}}}\right) /\left(1+\frac{p_{\text {heat }}^{o} \zeta_{i \text { heat }} \mathrm{MW}_{\mathrm{POM}}}{R T_{\text {heat }} C_{\mathrm{abs}}}\right)$

Note that $f_{i \text {,lost }}$ is independent of $C_{i, \text { tot }}$, which is unknown in this study because gas-phase concentrations were not measured.

The above equations indicate that the volatility of a compound is related to the activity of that compound in its absorbing phase. A greater degree of non-ideality will raise $C^{*}$ (Fig. 1a) and make the compound more volatile. Within a group of homologous compounds (i.e., the $n$-alkanes), $f_{\text {lost }}$ will increase for all compounds as the temperature change driving evaporation increases; furthermore, the distribution of $f_{\text {lost }}$ within the homologs (i.e., with molecular size) will shift as the composition of the absorbent changes (Fig. 1b). It is important to understand that the change in $f_{\text {lost }}$ with carbon number is most meaningful in the region of the curve where $f_{\text {lost }}$ changes sharply with carbon number. It is at this point where $C^{*}$ is closest to $C_{\mathrm{abs}}$, and thus where significant material exists in both the particulate and gas phases. At lower carbon numbers (i.e., approximately $\mathrm{C}_{20}$ ), almost all material exists in the gas phase, and therefore the ability to constrain $f_{\text {lost }}$ is limited.

Attempts to model gas-particle partitioning in smog chamber studies have required non-unity activity coefficients $\left(\zeta_{i}\right)$ for larger hydrocarbons in wood burning aerosol and secondary organic aerosol formed from $\alpha$-pinene oxidation. In contrast, the assumption of solution ideality is satisfactory for these large hydrocarbons partitioning in diesel exhaust (Jang et al., 1997). It is not known, however, which of these model aerosols best represents the absorbing phase(s) present in the atmosphere. We calculate values of $\zeta_{i}$ using a modified version of UNIFAC (Gmehling and Schiller, 1993), a group contribution activity coefficient model (Fredenslund et al., 1975). This version accounts for differences in molecular size between solvent and solute, and also performs relatively well for polar organic solvents. Along with experimental values for all compounds, we report theoretical $f_{\text {lost }}$ for the $n$ alkanes because their vapor pressures as a function of temperature are well-known (Lemmon and Goodwin, 2000).

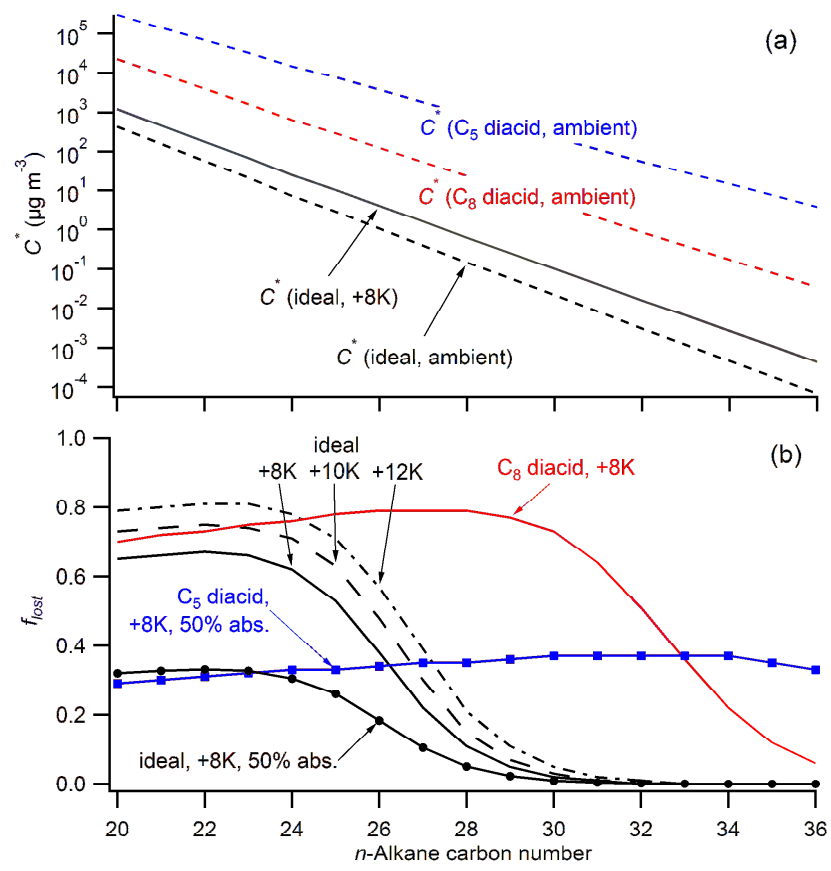

Fig. 1. (a) $C^{*}$ for $n$-alkanes vs. carbon number. An increase in $T$ of $8 \mathrm{~K}$ causes in increase in $C^{*}$, but the increase associated with a change from an ideal to a more oxygenated absorbent is much greater (according to a group-contribution activity coefficient model). (b) $N$-alkane $f_{\text {lost }}$ vs. carbon number when $C_{\mathrm{POM}}$ $=4 \mu \mathrm{g} \mathrm{m}^{-3}$. If the alkanes are assumed to form an ideal solution with the absorbing phase, $C^{*} \sim \mathrm{C}_{\mathrm{POM}}$ for a $\mathrm{C}_{24}$ alkane, and thus this is where $f_{\text {lost }}$ is greatest. If the heating is increased, the curve shifts upwards (to higher $f_{\text {lost }}$ ), but only slightly to the right (higher carbon number). If the absorbent is assumed to be $\mathrm{C}_{8}$ diacid, the enhanced activity of the alkanes shifts the curve primarily to the right. If only $50 \%$ of the particle-phase alkanes are absorbed and the rest are assumed to be non-volatile, $f_{\text {lost }}$ is reduced accordingly (lines with symbols). For a relatively polar absorbent (e.g., a $\mathrm{C}_{5}$ diacid), alkane $C^{*}$ s are large enough that partitioning is negligible under typical atmospheric $\mathrm{COA}$, and thus variation in $f_{\text {lost }}$ with carbon number from 20 to 36 is minor.

\section{Experimental}

\subsection{Field sites}

In the present study, ambient $\mathrm{PM}_{1.8}$ samples were collected in California's San Joaquin Valley at Fresno in a mixed residential / commercial neighborhood ( $\sim 400 \mathrm{~m}$ from CA Hwy. 41) during the summer of 2006 and winter of 2007, and at a rural agricultural research station $(\sim 100 \mathrm{~km} \mathrm{SW}$ of Fresno and $\sim 10 \mathrm{~km} \mathrm{SW}$ of Interstate (5) during the summer of 2007 and winter of 2008. Each sample was collected between the hours of $\sim 9 \mathrm{AM}$ to $\sim 3 \mathrm{PM}$ over five consecutive days in conjunction with health effect studies whose results will be published elsewhere. Filters remained in the samplers continuously over the 5 day collection period but all pumps and heaters were turned off during non-sample hours. Two 
consecutive 5-day samples were collected (for a total of ten days) in each season at both locations for a total of 16 samples ( 8 heated and 8 ambient). Ambient temperatures during the experiments ranged from $301 \pm 5 \mathrm{~K}$ in summer to $287 \pm 4 \mathrm{~K}$ in winter. Relative humidity $(\mathrm{RH})$ also varied seasonally, from $34 \pm 9 \%$ in summer to $60 \pm 13 \%$ in winter. Bulk $\mathrm{PM}_{1.8}$ filter samples were collected using Reference Ambient Air Samplers (RAAS) (Andersen Instruments) on pre-fired quartz filters $(D=45 \mathrm{~mm})$. Three separate RAAS samplers were operated simultaneously, each with an "ambient" leg and a "heated" leg wrapped in electrical resistance heating tape. Filters from these three samplers were composited for compound-specific analyses; for bulk analyses (i.e., elemental and organic carbon), measurements were made using each individual filter to support co-located comparisons of precision. Temperature was monitored just downstream of the filter in the heated leg, and the average temperature increases in the heated legs of two co-located samplers were $9.6 \pm 2.1$ and $8.2 \pm 2.7 \mathrm{~K}$ (quoted variation is $1 \sigma$ ). We used a $10 \mathrm{~K}$ temperature increase in all calculations, and results are similar if either an 8 or a $12 \mathrm{~K}$ increase are used (Fig. 1). Identical downstream quartz back-up filters were subtracted from the front filters to correct for gas-phase adsorption artifacts.

Additional measurements at the Fresno site during the summer of 20082009 and the winter of 2009/2010 were also included in the analysis to increase the statistical power of the study. These data consist only of bulk carbonaceous fractions - specifically, elemental carbon and organic carbon (see Sect. 3.2), and do not include any compound-specific analyses.

\subsection{Analyses}

Organic carbon (OC) and elemental carbon (EC) were quantified at the University of California-Davis with a Sunset Laboratory OC/EC Analyzer using the NIOSH 5040 thermo-optical method and sucrose as a calibration standard. Organic molecular markers were extracted by sonicating filters in dichloromethane followed by analysis using gas chromatography-mass spectrometry at the University of Wisconsin-Madison. The measured compounds included levoglucosan, cholesterol, 23 polycyclic aromatic hydrocarbons (PAHs), 16 hopanes/steranes, and 23 alkanes, including norpristane, pristane, phytane, and $n$-alkanes with carbon numbers from 17 to 36 . Trimethylsyl (TMS) derivatives of levoglucosan and cholesterol were analyzed. Field filter blanks were analyzed alongside all samples and average blank values were subtracted from all results. Backup filter values were subtracted from front filter values to correct for adsorption of gas-phase compounds onto the filter media. This will not correct for any semi-volatile compounds which are either adsorbed onto or absorbed into the particulate phase on the filter. However, this is simply equivalent to assuming that the PM sampled is already in equilibrium with the vapor phase (in which case, exposure to additional vapor while on the filter will not increase the concentration of the semi-volatile compounds in/on the PM phase).

\section{Results}

EC concentrations were slightly greater and more variable in the winter $\left(0.73 \pm 0.28 \mu \mathrm{g} \mathrm{m}^{-3}\right)$ than in the summer $\left(0.65 \pm 0.17 \mu \mathrm{g} \mathrm{m}^{-3}\right)$. The quoted uncertainty for these concentrations is $1 \sigma$ of the measured variation of concentrations across events. This trend reflects the increased emissions associated with residential and commercial heating as well as the formation of shallow inversion layers during the winter, which promotes higher PM concentrations. This PM accumulation is counterbalanced with the increased frequency of precipitation events during the winter, which tend to reduce concentrations. Seasonal patterns for OC concentrations (winter: $3.9 \pm 1.3 \mu \mathrm{g} \mathrm{m}^{-3}$ vs. summer: $3.7 \pm 0.8 \mu \mathrm{g} \mathrm{m}^{-3}$ ) matched the EC trends suggesting that anthropogenic sources contribute strongly to OC concentrations. Concentrations were greater at the urban site than the rural site for both [EC] $\left(0.72 \pm 0.27 \mu \mathrm{g} \mathrm{m}^{-3}\right.$ vs. $\left.0.62 \pm 0.13 \mu \mathrm{g} \mathrm{m}^{-3}\right)$ and [OC] $\left(3.9 \pm 1.1 \mu \mathrm{g} \mathrm{m}^{-3}\right.$ vs. $\left.3.3 \pm 1.1 \mu \mathrm{g} \mathrm{m}^{-3}\right)$.

The sum of detected $n$-alkane concentrations $\left(\mathrm{C}_{19}-\mathrm{C}_{36}\right)$ was nearly five times greater in summer $\left(28 \pm 44 \mathrm{ng} \mathrm{m}^{-3}\right)$ than in winter $\left(5.7 \pm 3.2 \mathrm{ng} \mathrm{m}^{-3}\right)$. Likewise, the sum of the concentrations for the 15 hopanes and steranes that were detected was over five times greater during the summer $\left(0.54 \pm 0.64 \mathrm{ng} \mathrm{m}^{-3}\right)$ than in winter $\left(0.10 \pm 0.08 \mathrm{ng} \mathrm{m}^{-3}\right)$. All three classes of alkanes were more abundant at the urban site (Fig. 2a, c, e); however, the difference between the two sites was less prominent when their concentrations were normalized to $[E C]$ (Fig. $2 b, d, f$ ). The two most abundant hopanes, $17 \beta(\mathrm{H}), 21 \alpha(\mathrm{H}), 30$-norhopane and $17 \alpha(\mathrm{H}), 21 \beta(\mathrm{H})$-hopane (average concentrations of 77 and $64 \mathrm{pg} \mathrm{m}^{-3}$, respectively) were well correlated $\left(r^{2}=0.98\right)$.

Out of the 23 PAHs that were measured, six were not detected, including three-ring molecules such as phenanthrene and anthracene. The lightest PAHs detected had MWs of $202 \mathrm{~g} \mathrm{~mol}^{-1}$ (fluoranthene and pyrene). In general, individual [PAH]s were greater in the winter (Fig. 2g), in contrast to the alkanes, and this was also true of $[\mathrm{PAH}] /[\mathrm{EC}] \mathrm{ra}-$ tios (Fig. 2h). The total PAH concentration ([PAH $]_{\text {tot }}$ ) was also greater in the winter than in summer, but summer variability was greater (winter: $0.20 \pm 0.09 \mathrm{ng} \mathrm{m}^{-3}$, summer: $0.17 \pm 0.16 \mathrm{ng} \mathrm{m}^{-3}$ ). The quoted summer mean and standard deviation of $[\mathrm{PAH}]_{\text {tot }}$ is dominated by a single anomalous ambient [retene] measurement in Fresno summertime of $0.31 \mathrm{ng} \mathrm{m}^{-3}$. Retene was not detected in any of the other seven summer samples, nor was it detected in the co-located heated samples. If retene is omitted from the analyses, summertime $[\mathrm{PAH}]_{\text {tot }}$ drops to $0.13 \pm 0.08 \mathrm{ng} \mathrm{m}^{-3}$.

Levoglucosan concentrations had seasonal trends similar to EC, OC, and PAHs with higher concentrations and greater variability in the winter than the summer $(43 \pm 18$ 

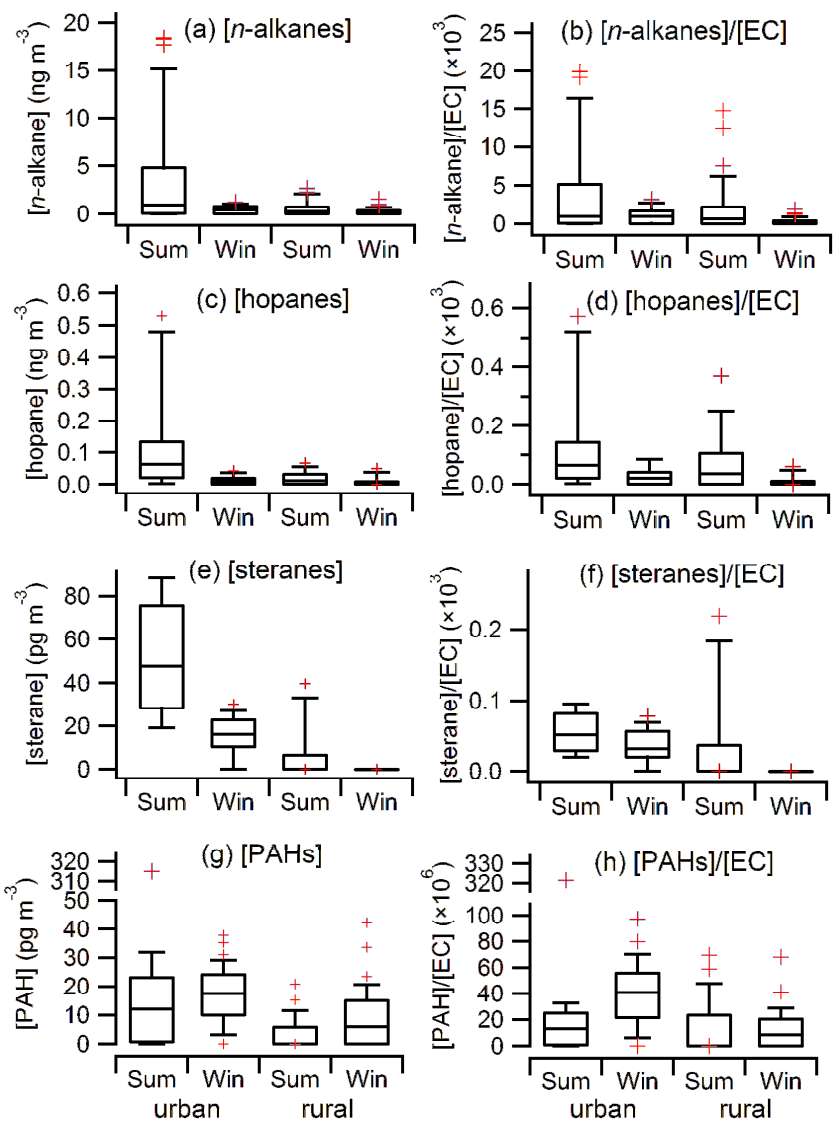

Fig. 2. Box and whisker plots (25/75\% and $10 / 90 \%$, respectively) of the concentrations of all compounds measured at ambient temperatures during the current study, as well as concentrations normalized to [EC]. (a) absolute and (b) normalized [ $n$-alkanes]; (c) absolute and (d) normalized [hopanes]; (e) absolute and (f) normalized [steranes]; (g) absolute and (h) normalized [PAHs].

vs. $7 \pm 8 \mathrm{ng} \mathrm{m}^{-3}$ ). Winter concentrations would likely have been much higher if samples had been collected at night when home heating with wood combustion is common in the SJV (Kleeman et al., 2008). Cholesterol concentrations were lower than any other compounds reported here, averaging only $1.0 \pm 0.9 \mathrm{ng} \mathrm{m}^{-3}$ in the summer and $0.3 \pm 0.3 \mathrm{ng} \mathrm{m}^{-3}$ in the winter. Thus the seasonal atterns of cholesterol were similar to those for hopanes/steranes and $n$-alkanes.

Figure 3 illustrates the fraction of each chemical species lost from the particle phase in the sample that was heated $\sim 10 \mathrm{~K}$ above the ambient temperature. Neither EC or OC concentrations had a statistically significant response to heating (Fig. 3a, b): $[\mathrm{EC}]_{\text {heat }} /[\mathrm{EC}]_{\mathrm{amb}}$ was $0.95 \pm 0.05$, and $[\mathrm{OC}]_{\text {heat }} /[\mathrm{OC}]_{\mathrm{amb}}$ was $1.02 \pm 0.04$ (quoted uncertainty for heated:ambient ratios is the $95 \%$ confidence interval). Heating caused only a slight volatilization of PAHs (excluding retene) in both seasons (winter $[\mathrm{PAH}]_{\text {heat }} /[\mathrm{PAH}]_{\mathrm{amb}}=$ $0.87 \pm 0.06$, summer $\left.[\mathrm{PAH}]_{\text {heat }} /[\mathrm{PAH}]_{\mathrm{amb}}=0.95 \pm 0.09\right) \mathrm{de}-$ spite the fact that the lighter PAHs considered in the anal- ysis have saturation concentrations that make them semivolatile according to absorptive partitioning theory (Fig. 3c). Retene was the exception to this trend, with almost complete loss of retene for a single heated/ unheated sample pair. Concentrations of the unsaturated hydrocarbons including hopanes/steranes and $n$-alkanes decreased significantly with mild heating (Fig. 3d, e), with the exception of $n$-alkanes in summer at the rural site. This reduction in alkane concentrations was greater at the urban site during the summer $(52 \%$ loss for hopane/steranes and $84 \%$ loss for $n$-alkanes) than in the winter ( $40 \%$ loss and $38 \%$ loss, respectively). In contrast, the mass of $n$-alkanes in the rural samples was actually $15 \%$ greater in the heated leg (Fig. 3e) during summer. However, if the backup filter subtraction is neglected, the fraction lost to heating was $18 \%$ at the rural site and $77 \%$ at the urban site. This can be seen in a plot of both front and backup filter concentrations vs. carbon number (Fig. 4), which shows that at the rural site in summer, front and backup filter $n$ alkane concentrations were approximately equal, while the backup filter concentrations were reduced in the heated leg. The OC on backup filters contains gas-phase compounds that adsorb onto the quartz, and these results therefore suggest that adsorption of rural VOCs is more reversible than for urban VOCs, which is consistent with more strongly-adsorbing compounds emitted in Fresno being removed from the atmosphere before reaching the rural site. Levoglucosan concentrations were reduced by $10 \%$ with heating, i.e., their apparent volatility was similar to the PAHs. Likewise, cholesterol concentrations did not experience a statistically significant change in response to heating (Fig. 3f).

\section{Discussion}

Both the seasonal patterns of molecular marker concentrations and their volatility behavior with mild heating suggest different partitioning mechanisms for PAHs on one hand, and hopane/steranes and $n$-alkanes on the other. Specifically, the reduced loss with heating and higher wintertime concentrations exhibited by the PAHs suggest that absorptive partitioning may only be a minor contributor to particle-phase concentrations. Previous studies have concluded that partitioning of PAHs into urban aerosols as a function of temperature is best explained by an adsorption mechanism (Yamasaki et al., 1982), and adsorption onto soot might dominate gasparticle partitioning of PAHs into of urban aerosols (Dachs and Eisenreich, 2000). A review of a broader range of ambient aerosols found that soot adsorption was likely responsible for particle-phase [PAH]s greater than those calculated for OA absorption (Lohmann and Lammel, 2004). We found that the loss of PAHs with heating ( $\left.f_{\text {lost }}\right)$ was lower on average at the urban site $(10 \pm 8 \%)$ than at the rural site $(20 \pm 8 \%)$, but was roughly equivalent in summer $(11 \pm 11 \%)$ and winter $(13 \pm 6 \%)$. This non-volatile behavior is consistent with adsorption of most of the particle-phase PAHs onto soot, and 

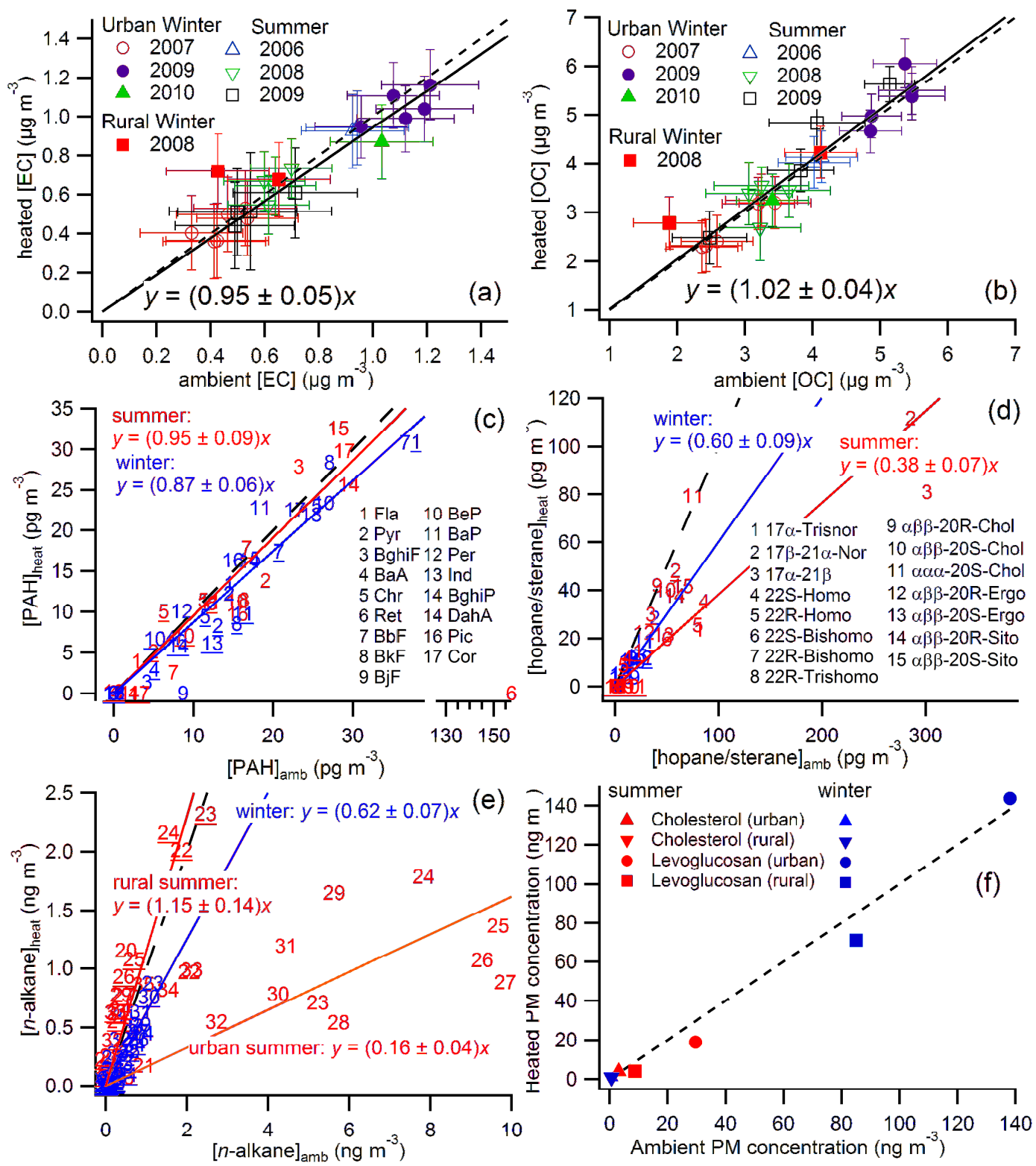

Fig. 3. Heated vs. ambient (unheated) concentrations. (a) EC (b) OC (c) PAHs (d) hopanes and steranes (e) $n$-alkanes (f) cholesterol and levoglucosan. In panels (c-e), rural values are underlined. Note that [EC] and [OC] data from additional field campaigns has been added to panels (a) and (b) to reduce the uncertainty in the linear regression. Also note that [EC] and [OC] concentrations were below quantification limits in the heated leg of the rural summer samples.

also with a greater number of surface sites per unit mass of soot near sources (i.e., at the urban site). According to the results of Yamaski et al. (1982), a change in T from 301 to $313 \mathrm{~K}$ would increase the adsorptive partitioning coefficient (defined analogously to $C^{*}$ ) of fluoranthene, pyrene, and benzopyrene by $76 \%, 70 \%$, and $86 \%$, respectively. In contrast, the calculated increase in $C^{*}$ for the $n$-alkanes associated with the same temperature increase is $470 \%$ for eicosane $\left(\mathrm{C}_{20}\right)$ and increases to $1600 \%$ for hexatricontane $\left(\mathrm{C}_{36}\right)$. Our results are consistent with a greater sensitivity to temperature of the absorption vs. the adsorption portioning coefficient.
Given the high values of $f_{\text {lost }}$ observed for the $n$-alkanes and hopanes/steranes, it is somewhat surprising that particlephase concentrations of these compounds were greater in summer than winter by a factor of five. Since the emissions sources of these compounds do not undergo five-fold increases in summer vs. winter, it is expected that seasonal changes to the absorbing particulate matter must be responsible for the differences in particle-phase concentrations. Closer inspection of the data reveals that $f_{\text {lost }}$ for the $n$-alkanes and hopanes was greatest during the summer at the urban site (Fig. 5), which would result from a 

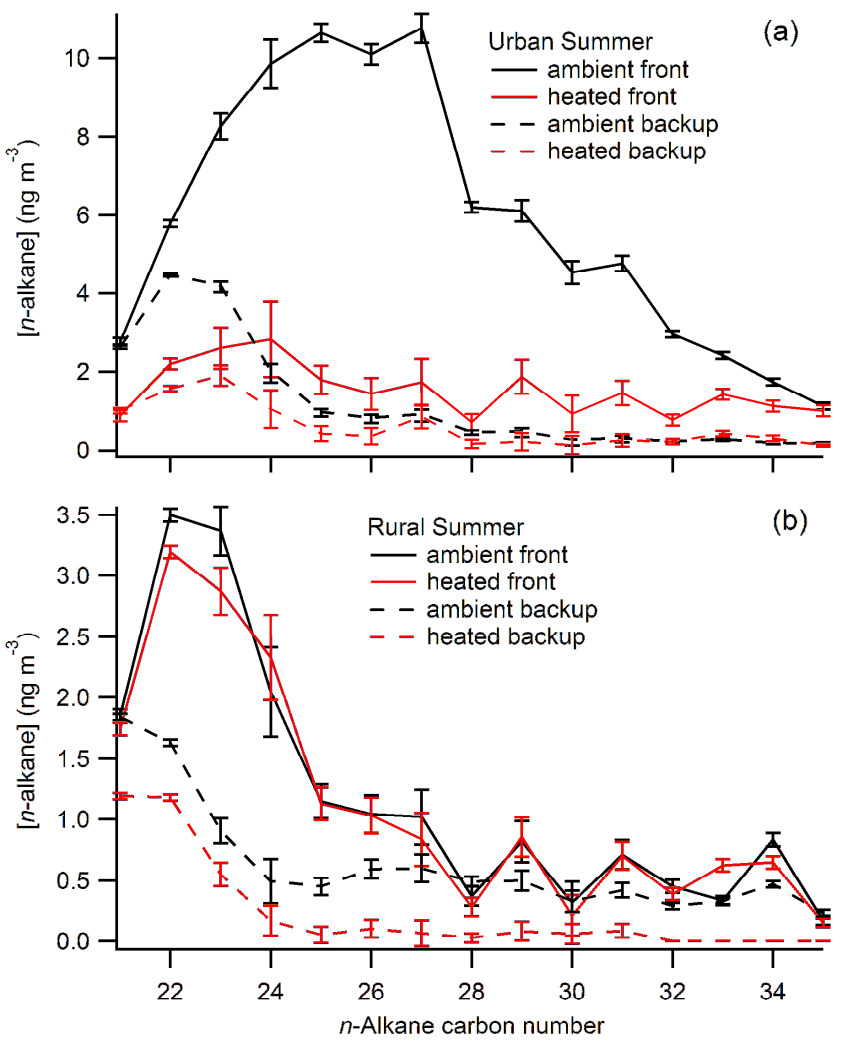

Fig. 4. Concentrations of $n$-alkanes as a function of carbon number. Results from both front (solid lines) and backup (dashed lines) filter are depicted. Color indicates sample leg, with black representing the ambient leg and red representing the heated leg. (a) Urban summer. (b) Rural summer.

greater capacity of the fresh urban particulate organic phase to absorb large hydrocarbons. The seasonal difference could be related to the lower daytime RH in the SJV summer, which would reduce the particle-phase water content and might therefore promote higher concentrations of the absorbing organic (non-aqueous) phase. This summertime increase in $C_{\text {abs }}$ would result in a roughly proportional increase in the particle-phase concentrations of $n$-alkanes and hopanes/steranes. The increase in humidity during wintertime may promote the sorption of organic material onto an aqueous phase, which might (like soot) be less sensitive to temperature than is absorptive partitioning. Furthermore, organic matter may absorb into or adsorb onto an aqueous phase, which would reduce the size of the organic phase available to absorb non-polar organic compounds. To summarize, our results suggest that particle-phase concentrations of large hydrocarbons are limited by the abundance of a relatively non-polar organic phase.

During the summer, $n$-alkane $f_{\text {lost }}$ increased with carbon number in the range $21-28$, and then decreased with carbon number from 28-35 (Fig. 6a). This pattern, particularly the decrease in loss with heating at higher carbon number, is consistent with group-contribution estimates of $\zeta$ as a (a) $n$-alkanes
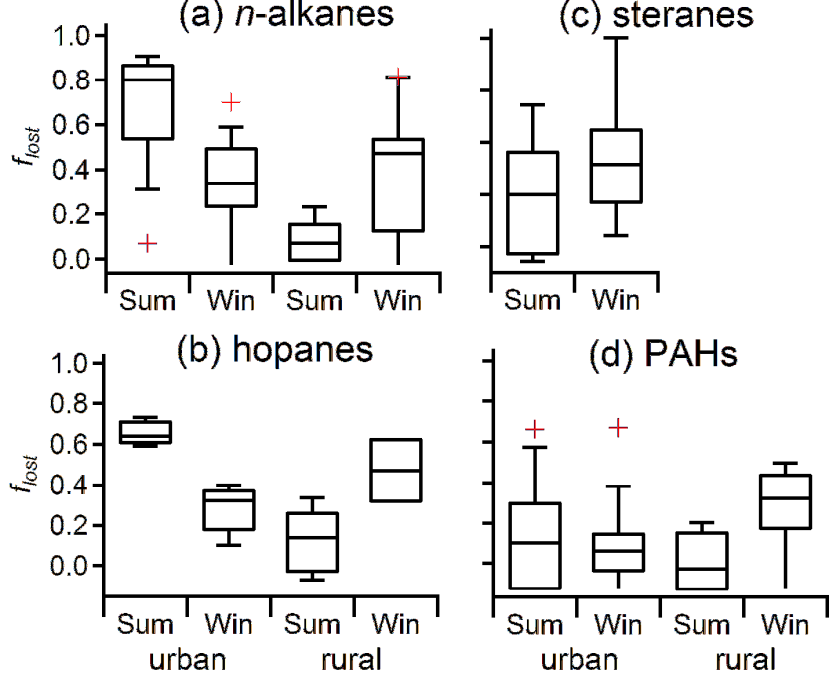

Fig. 5. Box and whisker plots (25/75\% and $10 / 90 \%$, respectively) depicting the fraction lost to mild heating $\left(f_{\text {lost }}\right)$ of various compound classes, separated by season and location. (a) $n$-alkanes. (b) hopanes. (c) steranes (which were not detected at the rural site). (d) PAHs.

function of MW. However, $f_{\text {lost }}$ approaches zero at a larger carbon number than predicted assuming the $n$-alkanes form an ideal solution in their absorbent. Relaxing the assumption of ideality and modelling the absorbent as a mixture of 40 compounds, including carbonyl compounds observed in vehicular emissions (Jakober et al., 2008), as a surrogate for light-duty vehicle particulate emissions (Chen et al., 2010) results in only minor changes in $f_{\text {lost }}$ with carbon number, because the predicted activity coefficients are close to unity. We also modelled the absorbent using surrogate compounds picked to represent organic aerosol factors identified by positive matrix factorization of high-resolution aerosol mass spectrometer data collected in Mexico City (Aiken et al., 2009). Specifically, Aiken et al. (2009) isolated a "hydrocarbon organic aerosol" (HOA) that had $\mathrm{O}: \mathrm{C}=0.16$ and $\mathrm{H}: \mathrm{C}=1.84$, and an "oxygenated organic aerosol" that had $\mathrm{O}: \mathrm{C}=0.60$ and $\mathrm{H}: \mathrm{C}=1.47$. We use 12-hydroxy-dodecanal $(\mathrm{O}: \mathrm{C}=0.17, \mathrm{H}: \mathrm{C}=1.83, \mathrm{MW}=198)$ and 5-oxo-pentanoic acid $(\mathrm{O}: \mathrm{C}=0.60, \mathrm{H}: \mathrm{C}=1.60, \mathrm{MW}=116)$ as surrogates for HOA and OOA, respectively. Other highly oxygenated surrogate organic phases, such as a model fulvic acid compound (Buffle et al., 1977) and glyoxal oligomers, produced results similar to 5-oxo-pentanoic acid. $f_{\text {lost }}$ was reduced in the winter for the $n$-alkanes (Fig. 6b). Still, a decrease in $f_{\text {lost }}$ was evident in larger $n$-alkanes (with carbon numbers above 29) during the winter, suggesting that, as with the summer samples, the absorbing phase was about as polar as azelaic $\left(\mathrm{C}_{8}\right)$ acid. 


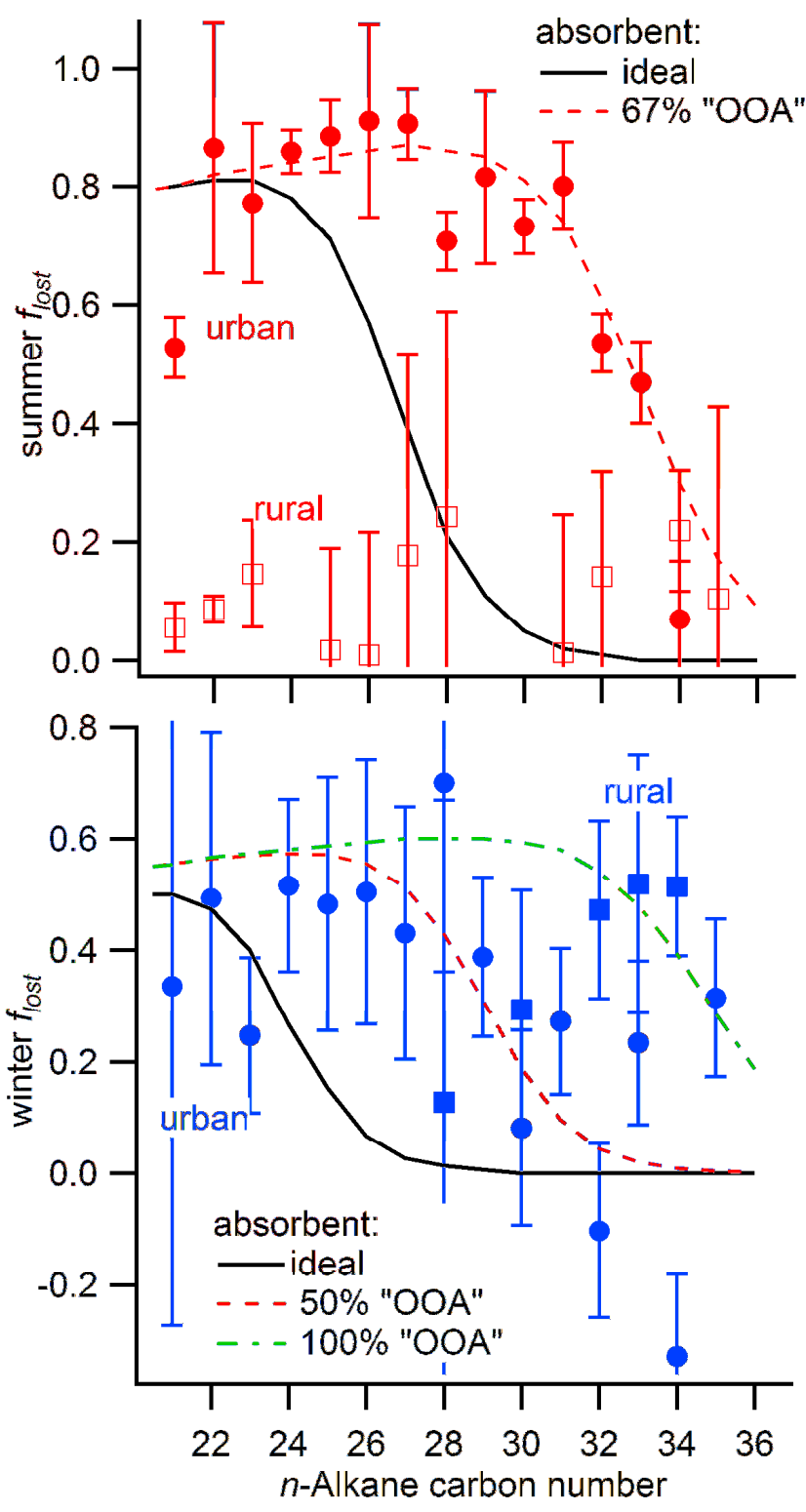

Fig. 6. Observed values of $n$-alkane $f_{\text {lost }}$ (circles are urban, squares are rural) as a function of carbon number, along with those predicted using a group-contribution activity coefficient model with various assumptions regarding the composition of the absorbing phase (lines). (a) Summer results. Rural values are depicted as open symbols to indicate that backup-filter subtraction was not performed. (b) Winter results.

The fraction of the $n$-alkanes lost with mild heating was substantial in the urban summer; in sharp contrast, [ $n$ alkane $]_{\text {heat }} /[n \text {-alkane }]_{\text {amb }}$ ratios were typically greater than one in the rural summer. This was primarily due to reduced [n-alkane] on the heated leg backup filter, which traps gasphase compounds mainly by adsorption onto the surface of quartz fibres. When concentrations only on the front filter are considered, rural summer $n$-alkane concentrations were slightly greater in the ambient leg than in the heated leg (Fig. 5a). PM analysis by aerosol mass spectrometry has indicated that while urban organic aerosols are a mixture of a "hydrocarbon-like" and "oxygenated" organic aerosol, background/rural sites tend to be dominated by oxygenated organic aerosol (Zhang et al., 2007; Aiken et al., 2009). It therefore seems likely that the lower rural $f_{\text {lost }}$ of $n$-alkanes is due to a more oxygenated phase into which larger, unsaturated hydrocarbons cannot absorb efficiently. For example, in an organic phase represented by glutaric acid (blue lines on Fig. 1a), $C^{*}$ is greater than $10 \mu \mathrm{g} \mathrm{m}^{-3}$ for all $n$-alkanes studied, and greater than $100 \mu \mathrm{g} \mathrm{m}^{-3}$ for all $n$-alkanes with carbon number less than 33 . Thus, under normal ambient conditions, nearly all of the $n$-alkanes will remain in the gas phase rather than absorb into a glutaric acid POM phase. The $n$-alkanes present in the PM must therefore partition via a different mechanism (e.g., adsorption to soot), one unaffected by a $10 \mathrm{~K}$ increase in temperature.

Volatility for hopanes/steranes was also greater in the summer than winter $\left(f_{\text {lost }}=58 \%\right.$ vs. $\left.f_{\text {lost }}=36 \%\right)$, matching the trends exhibited by $n$-alkanes. The summertime value suggests that these compounds have similar volatility as $\mathrm{C}_{29}-\mathrm{C}_{32} n$-alkanes under atmospherically-relevant conditions. The hopanes and steranes quantified had carbon numbers ranging from 27 to 32, which implies that hopanes/steranes have a tendency to evaporate that is equal or only slightly less than $n$-alkanes with similar MW. The summertime $f_{\text {lost }}$ for hopanes peaked at a carbon number of 30, again consistent with an absorbing phase about as polar at glutaric acid. Like the $n$-alkanes, hopane/steranes had a reduced tendency to evaporate in the winter, with even greater reductions at the rural summer site. Overall, the similarity between hopane/steranes and $n$-alkanes suggests that hopanes/steranes have saturation concentrations on the order of $0.1-10 \mu \mathrm{g} \mathrm{m}^{-3}$, depending on the chemical identity of the absorbing phase, and should generally be considered semivolatile.

\section{Conclusions}

The particle-phase concentrations of $n$-alkanes, PAHs, hopanes, steranes, levoglucosan, and cholesterol were measured in both summer and winter at both an urban and rural location within the San Joaquin Valley in central California. We compared the daytime concentrations on filters collected at ambient temperatures, and on filters heated to $\sim 10 \mathrm{~K}$ above ambient, and calculated the fraction of each compound lost $\left(f_{\text {lost }}\right)$ at each site and during each season. The concentrations of $\mathrm{C}_{20}-\mathrm{C}_{36}$ n-alkanes and the $f_{\text {lost }}$ values for these compounds were highest in the urban summer. $N$-alkane $f_{\text {lost }}$ values were lowest in the rural summer, and were intermediate during both winter campaigns. Other alkanes (i.e., hopanes and steranes) displayed a similar spatial and temporal pattern. This suggests that the particle-phase 
concentrations of larger alkanes were limited by the amount of a chemically compatible absorbing phase, and that even compounds with as many as 30 carbon atoms should be considered semi-volatile in polluted regions such as the SJV. If these compounds form an ideal solution during absorption, they would essentially be considered non-volatile; however, a group-contribution activity-coefficient model can be reconciled with these results if the absorbing phase is assumed to have similar O:C and $\mathrm{H}: \mathrm{C}$ ratios as typically observed for ambient organic aerosols by high-resolution aerosol mass spectrometry. The highly oxygenated organic aerosol that is ubiquitous at remote continental locations may not be an effective absorbent of such large hydrocarbons, and we recommend against the use of unity activity coefficients when modelling gas-particle partitioning of such compounds.

In contrast, concentrations of PAHs, levoglucosan, and bulk carbonaceous components (i.e., EC and OC) were not reduced or only slightly reduced by mild heating during all campaigns. While this is not unexpected for levoglucosan due to its low vapour pressure, it suggests that PAHs may partition to the particle phase primarily by a mechanism other that absorption. The constant behaviour in bulk carbonaceous components suggests that compounds traditionally used as markers of vehicular PM emissions (i.e., hopanes, steranes) may be more volatile on average than the emissions they purport to represent; however, similarly designed studies that focus on specific sources instead of more complex ambient samples are needed to fully test this hypothesis. Finally, we note that this study represents only 40 total days of ambient PM sampling; longer-term measurements of the fraction of specific compounds with heating will be required to more fully characterize the ability of ambient PM to act as an absorbent.

Acknowledgements. The authors would like to thank Jamie Schauer and Brandon Shelton of the University of Wisconsin-Madison for performing all GC-MS analyses, and acknowledge the United States Environmental Protection Agency and the San Joaquin Valley Aerosol Health Effects Research Center for funding this research. Although the research described in the article has been funded wholly or in part by the United States Environmental Protection Agency through grant RD-83241401-0 to the University of California, Davis, it has not been subject to the Agency's required peer and policy review and therefore does not necessarily reflect the views of the Agency and no official endorsement should be inferred.

Edited by: M. Gysel

\section{References}

Aiken, A. C., Salcedo, D., Cubison, M. J., Huffman, J. A., DeCarlo, P. F., Ulbrich, I. M., Docherty, K. S., Sueper, D., Kimmel, J. R., Worsnop, D. R., Trimborn, A., Northway, M., Stone, E. A., Schauer, J. J., Volkamer, R. M., Fortner, E., de Foy, B., Wang, J., Laskin, A., Shutthanandan, V., Zheng, J., Zhang, R., Gaffney, J., Marley, N. A., Paredes-Miranda, G., Arnott, W. P., Molina, L. T., Sosa, G., and Jimenez, J. L.: Mexico City aerosol analysis during MILAGRO using high resolution aerosol mass spectrometry at the urban supersite (T0) - Part 1: Fine particle composition and organic source apportionment, Atmos. Chem. Phys., 9, 66336653, doi:10.5194/acp-9-6633-2009, 2009.

Arp, H. P. H., Schwarzenbach, R. P., and Goss, K.-U.: Ambient gas/particle partitioning. 2: The influence of particle source and temperature on sorption to dry terrestrial aerosols, Environ. Sci. Technol. 42, 5951-5957, 2008.

Atkinson, R. and Arey, J.: Atmospheric degradation of volatile organic compounds, Chem. Rev., 103, 4605-4638, 2003.

Buffle, J., Greter, F. L., and Haerdi, W.: Measurement of complexation properties of humic and fulvic acids in natural waters with lead and copper ion-selective electrodes, Anal. Chem., 49, 216222, 1977.

Chen, J., Jakober, C., Clegg, S., and Kleeman, M. J.: Theoretical vs. observed gas-particle partitioning of carbonyl emissions from motor vehicles, J. Air Waste Manage., 60, 1237-1244, 2010.

Chen, L.-W. A., Watson, J. G., Chow, J. C., and Magliano, K. L.: Quantifying $\mathrm{PM}_{2.5}$ source contributions for the San Joaquin valley with multivariate receptor models, Environ. Sci. Technol., 41, 2818-2826, 2007.

Chow, J. C., Watson, J. G., Lowenthal, D. H., Solomon, P. A., Magliano, K. L., Ziman, S. D., and Richards, L. W.: PM10 source apportionment in California's San Joaquin valley, Atmos. Environ., 26, 3335-3354, 1992.

Chow, J. C. and Watson, J.: Review of $\mathrm{PM}_{2.5}$ and $\mathrm{PM}_{10}$ apportionment for fossil fuel combustion and other sources by the chemical mass balance receptor model, Energ. Fuel., 16, 222-260, 2002.

Chow, J. C., Watson, J. G., Lowenthal, D. H., Chen, L. W. A., Zielinska, B., Mazzoleni, L. R., and Magliano, K. L.: Evaluation of organic markers for chemical mass balance source apportionment at the Fresno Supersite, Atmos. Chem. Phys., 7, 17411754, doi:10.5194/acp-7-1741-2007, 2007.

Dachs, J. and Eisenreich, S.: Adsorption onto aerosol soot carbon dominates gas-particle partitioning of polycyclic aromatic hydrocarbons, Environ. Sci. Technol., 34, 3690-3697, 2000.

Fraser, M., Buzcu, B., Yue, Z., McGaughey, G., Desai, N., Allen, D., Seila, R., Lonneman, W., and Harley, R.: Separation of fine particulate matter emitted from gasoline and diesel vehicles using chemical mass balancing techniques, Environ. Sci. Technol., 3904-3909, 2003.

Fredenslund, A., Jones, R., and Prausnitz, J.: Group-contribution estimation of activity-coefficients in nonideal liquid-mixtures, AICHE J., 21, 1086-1099, 1975.

Gmehling, J., Li, J., and Schiller, M.: A modified unifac model. 2. Present parameter matrix and results for different thermodynamic properties, Ind. Eng. Chem. Res., 32, 178-193, 1993.

Jakober, C. A., Robert, M. A., Riddle, S. G., Destaillats, H., Charles, M. J., Green, P. G., and Kleeman, M. J.: Carbonyl emissions from gasoline and diesel motor vehicles, Environ. Sci. 
Technol., 42, 4697-4703, 2008.

Jang, M., Kamens, R. M., Leach, K. B., and Strommen, M. R.: A thermodynamic approach using group contribution methods to model the partitioning of semivolatile organic compounds on atmospheric particulate matter, Environ. Sci. Tech., 31, 28052811, 1997.

Kleeman, M. J., Riddle, S. G., and Jakober, C. A.: Size distribution of particle-phase molecular markers during a severe winter pollution episode, Environ. Sci. Tech., 42, 6469-6475, 2008.

Kleeman, M. J., Riddle, S. G., Robert, M. A., Jakober, C. A., Fine, P. M., Hays, M. D., Schauer, J. J., and Hannigan, M. P.: Source apportionment of fine $\left(\mathrm{PM}_{1.8}\right)$ and ultrafine $\left(\mathrm{PM}_{0.1}\right)$ airborne particulate matter during a severe winter pollution episode, Environ. Sci. Tech., 43, 272-279, 2009.

Lambe, A. T., Miracolo, M. A., Hennigan, C. J., Robinson, A. L., and Donahue, N. M.: Effective rate constants and uptake coefficients for the reactions of organic molecular markers ( $n$ alkanes, hopanes, and steranes) in motor oil and diesel primary organic aerosols with hydroxyl radicals, Environ. Sci. Technol., 43, 8794-8800, 2009.

Lemmon, E. W. and Goodwin, A. R. H.: Critical properties and vapor pressure equation for alkanes $\mathrm{C}_{n} \mathrm{H}_{2 n+2}$ : Normal alkanes with $\mathrm{n}<=36$ and isomers for $\mathrm{n}=4$ through $\mathrm{n}=9$, J. Phys. Chem. Ref. Data, 29, 1-39, 2000.

Lin, L., Lee, M. L., and Eatough, D. J.: Review of recent advances in detection of organic markers in fine particulate matter and their use for source apportionment, J. Air Waste Manage., 60, 3-25, 2010.

Lohmann, R. and Lammel, G.: Adsorptive and absorptive contributions to the gas-particle partitioning of polycyclic aromatic hydrocarbons: State of knowledge and recommended parametrization for modeling, Environ. Sci. Technol., 38, 3793-3803, 2004.

Magliano, K. L., Hughes, V. M., Chinkin, L. R., Coe, D. L., Haste, T. L., Kumar, N., and Lurmann, F. W.: Spatial and temporal variations in $\mathrm{PM}_{10}$ and $\mathrm{PM}_{2.5}$ source contributions and comparison to emissions during the 1995 integrated monitoring study, Atmos. Environ., 33, 4757-4773, 1999.

Miracolo, M. A., Presto, A. A., Lambe, A. T., Hennigan, C. J., Donahue, N. M., Kroll, J. H., Worsnop, D. R., and Robinson, A. L.: Photo-oxidation of low-volatility organics found in motor vehicle emissions: Production and chemical evolution of organic aerosol mass, Environ. Sci. Technol., 44, 1638-1643, 2010.

Pankow, J. F. and Bidleman, T. L.: Interdependence of the slopes and intercepts from log-log correlations of measured gas particle partitioning and vapor-pressure .1. Theory and analysis of available data, Atmos. Environ., 26, 1071-1080, 1992.

Pankow, J. F. :An absorption-model of gas-particle partitioning of organic-compounds in the atmosphere, Atmos. Environ., 28, 185-188, 1994.

Phuleria, H. C., Sheesley, R. J., Schauer, J. J., Fine, P. M., and Sioutas, C.: Roadside measurements of size-segregated particulate organic compounds near gasoline and diesel-dominated freeways in Los Angeles, CA, Atmos. Environ., 41, 4653-4671, 2007.
Ramdahl, T.: Retene - A molecular marker of wood combustion in ambient air, Nature, 306, 580-583, 1983.

Riddle, S. G., Robert, M. A., Jakober, C. A., Hannigan, M. P., and Kleeman, M. J.: Size-resolved source apportionment of airborne particle mass in a roadside environment, Environ. Sci. Technol., 42, 6580-6586, 2008.

Rinehart, L., Fujita, E., Chow, J., Magliano, K., and Zielinska, B.: Spatial distribution of $\mathrm{PM}_{2.5}$ associated organic compounds in central California, Atmos. Environ. 40, 290-303, 2006.

Robinson, A. L., Subramanian, R., Donahue, N. M., BernardoBricker, A., and Rogge, W. F.: Source apportionment of molecular markers and organic aerosols, 1. Polycyclic aromatic hydrocarbons and methodology for data visualization, Environ. Sci. Technol., 40, 7803-7810, 2006.

Robinson, A. L., Donahue, N. M., Shrivastava, M. K., Weitkamp, E. A., Sage, A. M., Grieshop, A. P., Lane, T. E., Pierce, J. R., and Pandis, S. N.: Rethinking organic aerosols: Semivolatile emissions and photochemical aging, Science, 315, 1259-1262, 2007.

Rogge, W., Hildemann, L., Mazurek, M., Cass, G., and Simonelt, B.: Sources of fine organic aerosol. 1. Charbroilers and meat cooking operations, Environ. Sci. Technol., 25, 1112-1125, 1991.

Rogge, W., Hildemann, L., Mazurek, M., Cass, G., and Simoneit, B.: Sources of fine organic aerosol, 4. particulate abrasion products from leaf surfaces of urban plants, Environ. Sci. Technol., 27, 2700-2711, 1993.

Schauer, J. J., Rogge, W. F., Hildemann, L. M., Mazurek, M. A., Cass, G. R., and Simoneit, B. R. T.: Source apportionment of airborne particulate matter using organic compounds as tracers, Atmos. Environ., 30, 3837-3855, 1996.

Schauer, J. J. and Cass, G. R.: Source apportionment of wintertime gas-phase and particle-phase air pollutants using organic compounds as tracers, Environ. Sci. Technol., 34, 1821-1832, 2000.

Simoneit, B.: A review of biomarker compounds as source indicators and tracers for air pollution, Environ. Sci. Pollut. R., 6, 159-169, 1999.

Simoneit, B.: Biomass burning - a review of organic tracers for smoke from incomplete combustion, Appl. Geochem., 17, 129162, 2002.

Yamasaki, H., Kuwata, K., and Miyamoto, H.: Effects of ambient-temperature on aspects of airborne polycyclic aromatichydrocarbons, Environ. Sci. Technol. 16, 189-194, 1982.

Zhang, Q., Jimenez, J. L., Canagaratna, M. R., Allan, J. D., Coe, H., Ulbrich, I., Alfarra, M. R., Takami, A., Middlebrook, A. M., Sun, Y. L., Dzepina, K., Dunlea, E., Docherty, K., DeCarlo, P. F., Salcedo, D., Onasch, T., Jayne, J. T., Miyoshi, T., Shimono, A., Hatakeyama, S., Takegawa, N., Kondo, Y., Schneider, J., Drewnick, F., Borrmann, S., Weimer, S., Demerjian, K., Williams, P., Bower, K., Bahreini, R., Cottrell, L., Griffin, R. J., Rautiainen, J., Sun, J. Y., Zhang, Y. M., and Worsnop, D. R.: Ubiquity and dominance of oxygenated species in organic aerosols in anthropogenically-influenced Northern Hemisphere midlatitudes, Geophys. Res. Lett., 34, L13801, doi:10.1029/2007GL029979, 2007. 